\title{
POLÍTICAS EDUCACIONAIS DE FORMAÇÃO CONTINUADA E VALORIZAÇÃO DOS DOCENTES DO PROGRAMA DE EDUCAÇÃO DE JOVENS E ADULTOS: análise das ações SME/GEJA-RJ, face ao PNE (2014-2018)
}

\author{
Carla da Mota Souza' \\ Jésus de Alvarenga Bastos² \\ Maria de Lourdes Pinto de Almeida ${ }^{3}$
}

\begin{abstract}
RESUMO
O artigo pauta-se em tese realizada no município do RJ, entre 2014-2018. Objetivouse analisar as políticas educacionais de formação continuada e valorização dos professores do Programa de Educação de Jovens e Adultos (Peja), face as Metas 15, 16, 17 e 18, do Plano Nacional de Educação (PNE 2014-2024)), dirigidas pelos agentes da Gerência de Educação de Jovens e Adultos (Geja/SME-RJ). O Peja é um programa específico do município, que atende aos alunos jovens e adultos que não estudaram na idade regular. Constitui-se como: pesquisa qualitativa; método do Materialismo Histórico-Dialético; análise de conteúdo de Bardin e Bourdieu como referencial teórico, com os conceitos: agente, campo, habitus, capital cultural e violência simbólica. Conclui-se que, embora a Geja/SME/RJ fomente políticas voltadas à formação continuada e valorização dos professores do Peja, muito precisa fazer, pois dos 1.134 professores, 102 ou 9\% deles não possuem o nível superior completo, exigido pela Meta 15. A Meta 16, que prevê formação de $50 \%$ dos professores, em nível de pós-graduação até o final da vigência do Plano, em 2024, é possível ser cumprida, embora difícil, pois 242 professores, correspondendo apenas a 21,35\%, possuem formação desejada. A Meta 17 que prevê a equiparação do rendimento médio dos professores com os demais profissionais de escolaridade equivalente, mostra-se coerente com o que é estipulado pelo PNE. A Meta 18 que estabelece a criação e regulamentação do Plano de Cargos, Salário e Carreira do Magistério, vigora no município, porém este apresenta distorções gritantes que estão em processo de ajustes.
\end{abstract}

Palavras-chave: Formação Continuada. Valorização. Peja.

\footnotetext{
1 Doutora em Educação. Universidade Federal Fluminense - UFF. Professora da Prefeitura Municipal do Rio de Janeiro. Orcid iD: https://orcid.org/0000-0003-1316-674X. E-mail: carllamotta@hotmail.com

2 Doutor em Educação. Universidade Federal Fluminense - UFF. ORCID iD: http://orcid.org/0000-0003-3016-3321. E-mail: jesusbastos@terra.com.br

3 Doutora em Filosofia, História e Educação pela FE da Universidade Estadual de Campinas (2001). Pós-doutorado em Ciência Tecnologia e Sociedade pela Unicamp. ORCID iD: http://orcid.org/0000-0001-8515-2908. E-mail: Malu04@gmail.com
} 


\title{
EDUCATIONAL POLICIES FOR CONTINUING EDUCATION AND APPRECIATION OF
}

\author{
THE TEACHERS OF THE YOUTH AND ADULT EDUCATION PROGRAM: analysis of
}

\author{
SME/GEJA-RJ actions, in relation to PNE (2014-2018)
}

\begin{abstract}
The article is based on a thesis carried out in the city of RJ, between 2014-2018. The objective was to analyze the educational policies of continuing education and appreciation of the teachers of the Youth and Adult Education Program (Peja), in response to Goals 15, 16, 17 and 18 of the National Education Plan (PNE 2014-2024), by agents of the Youth and Adult Education Management (Geja / SME-RJ). The Peja is a specific program of the municipality for young and adult students who did not study at the regular age. It is constituted as qualitative research, method of Historical-Dialectical Materialism, content analysis of Bardin and Bourdieu as a theoretical framework based on these concepts: agent, field, habitus, cultural capital and symbolic violence. It is concluded that, although Geja/SME/RJ encourages policies aimed at continuing education and valorization of Peja teachers, much needs to be done, because from 1,134 teachers, 102 or $9 \%$ of them have not finished Higher Education studies as required by Goal 15. Although difficult, the Goal 16, which provides for the training of $50 \%$ of teachers at the postgraduate level by the end of the Plan in 2024, can be achieved, because 242 teachers, corresponding to only $21.35 \%$, possess the required qualification. Goal 17, which provides for the equalization of the average income of teachers with that of other professionals of equivalent level of education, is consistent with PNE. Goal 18, which establishes and regulates the career plan, salary, and teaching career, is in force in the municipality, but it also has striking distortions that are in the process of adjustment.
\end{abstract}

Keywords: Continuing Education. Valorization. Peja.

\section{POLIITICAS EDUCATIVAS DE FORMACIÓN CONTINUA Y VALORIZACIÓN DE LOS DOCENTES DEL PROGRAMA DE EDUCACIÓN DE JÓVENES Y ADULTOS: análisis de SME/GEJA- RJ, frente al PNE (2014-2018)}

\section{RESUMEN}

El artículo se basa en una tesis realizada en la ciudad de Río de Janeiro, entre 20142018. El objetivo fue analizar las políticas educativas de educación continua y la apreciación de los docentes del Programa de Educación de Jóvenes y Adultos (PEJA), en respuesta a las Metas 15, 16, 17 y 18 del Plan Nacional de Educación (PNE 2014-2024), por agentes de la Dirección de Educación de Jóvenes y Adultos (Geja / SME-RJ). La PEJA es un programa específico del municipio para estudiantes jóvenes y adultos que no estudiaron en la edad regular. Fue una investigación cualitativa basada en Bardin y Bourdieu como referencial teórico. Conclusión: aunque Geja / SME / RJ promueve políticas dirigidas a la capacitación continua y la apreciación de los maestros de Peja, es necesario hacerlo mucho más; ya que de los 1.134 maestros, 102 osea el $9 \%$ no tienen el nivel superior completo requerido por el 
Objetivo 15. El Objetivo 16, que prevé la capacitación del $50 \%$ de los maestros a nivel de posgrado al final del Plan en 2024, se puede lograr, aunque es difícil, porque 242 maestros, correspondientes de solo el 21.35\%, reciben la capacitación deseada. El objetivo 17, que prevé la igualdad de ingreso promedio de los docentes con otros profesionales de nivel equivalente de educación, es consistente con el PNE. La Meta 18, que establece y regula el Plan de carrera, salario y carrera del magisterio, está vigente en el municipio, pero también tiene distorsiones notables que están en proceso de ajuste.

Palabras clave: Formación continua. Valorización. Peja.

\section{INTRODUÇÃO}

A formação e valorização dos professores têm se configurado como proposta política central para que ocorra um salto qualitativo na educação em todas as modalidades de ensino no País. Embora haja consenso desta concepção, muito ainda precisa ser feito para que os textos legais vigorem na práxis. E quando se analisa a área da Educação de jovens e Adultos (EJA), o descompasso é mais marcante. A EJA passou a ter um pouco mais de notoriedade no País com a Constituição da República Federativa do Brasil de 1988. De lá para cá, ainda não encontrou campo fértil necessário para se firmar enquanto política compensatória, mediante as desigualdades sociais no País.

Essas desigualdades são expressas pelo Pnad 2014 - Instituto Brasileiro de Geografia e Estatística (IBGE), que divulgou a taxa de analfabetismo de $8,3 \%$ e do analfabetismo funcional, de $17,6 \%$ da população brasileira. Ainda segundo o IBGE (2014), a população cresceu no mesmo ano, passando para 202,7 milhões de habitantes. Portanto, $(8,3 \%+17,6 \%=25,9 \%)$ o percentual da população brasileira em estado de fragilidade e subalternização é da ordem de 52.499.300 indivíduos. Fato preocupante para qualquer democracia.

Essa distorção social acaba sendo agravada com a má formação dos professores pois, grande parte não consegue auxiliar os alunos, que evadem das escolas. Segundo Scheibe (2006), são poucos os cursos de Pedagogia a proporem componentes curriculares de aprofundamento para a modalidade de Educação de Jovens e Adultos (EJA); poucas disciplinas 
optativas são oferecidas para complementar a formação docente, que atenda às necessidades dos alunos do Peja. Há distinção entre as características e condições dos cursos oferecidos à noite e no período diurno. Essa realidade leva a concluir que, em virtude do despreparo dos alunos das licenciaturas, muitos professores que integram o corpo docente das escolas com a modalidade da EJA, necessitem de adequações em sua formação. Soares (2008) revelou em sua pesquisa, que:

[..] até o ano de 2006, antes da homologação das Novas Diretrizes Curriculares, havia no Brasil, segundo dados do Inep, 27 cursos de pedagogia com habilitação em educação de jovens e adultos, de um universo de 1.698 cursos existentes, distribuídos em três das cinco regiões geográficas do País (p. 65).

Esse quadro vem mudando, mas o despreparo ainda é marcante nas salas de aulas dos vários municípios brasileiros. Pesquisas recentes na área apontam: "[...] em sua prática as marcas da precarização e, embora a despeito da sua criatividade e compromisso, têm sua docência constituída na improvisação e no aligeiramento" (CAPUCHO, 2012). Ribas (2013), conclui: "[...] um dos motivos que leva o aluno a evadir da EJA, sendo novamente excluído, é a metodologia utilizada pelo professor em sala de aula". Os autores, Laffin e Gaya (2013), também constataram em sua pesquisa, que "no campo de formação de professores à EJA, as práticas utilizadas pelos docentes não correspondem às especificidades dos alunos dessa modalidade de ensino".

Mediante esse descompasso formativo e, por conseguinte, (des)valorativo do cenário educacional brasileiro, optou-se por focar as lentes da pesquisa para o macro campo do município do Rio de Janeiro, em virtude da proximidade da pesquisadora com o tema e com o campo de trabalho. Assim, o objetivo geral foi: analisar se as políticas educacionais de formação continuada e valorização dos professores do Programa de Educação de Jovens e Adultos (Peja), do macro campo da Secretaria Municipal de Educação do Rio de Janeiro (SME- RJ), fomentadas pelos agentes da Gerência de Educação de Jovens e Adultos (Geja), estão em 
consonância com o Plano Nacional de Educação (PNE), face as Metas 15, 16, 17 e 18, no período de 2014-2018.

Visando dar maior sustentação à tese foram estabelecidos outros objetivos específicos, que são: identificar como/quais são escolhidas as políticas voltadas à formação continuada e valorização dos professores do Peja, mediante a relação de poder simbólico advindo da SME-RJ e o capital cultural dos gerentes da Geja, ao direcionarem ações formativas aos seus professores. Problematizar, a partir do senso prático/habitus dos professores elementos de GED (descrito na pesquisa como Acompanhantes), a escuta perceptiva entre políticas praticadas pela Geja no que tange à formação e valorização dos professores do Peja e seus efeitos no campo educacional. Saber quais os requisitos formativos para que os professores ingressem no quadro funcional de professores do Peja, entre as normas estabelecidas no campo teórico e aquelas que vigoram na prática. Compreender os parâmetros pela qual a Geja avalia as políticas de formação continuada e valorização dos professores do Peja implementadas por ela, tendo como norteador o PNE.

O atual Plano Nacional de Educação (PNE 2014-2024), resultante da Lei $n^{\circ} 13.005 / 2014$, em vigor, foi escolhido como suporte documental central da pesquisa, para que fossem analisadas as Metas, 15, 16, 17 e 18 e suas diretrizes, perante as ações da SME-RJ, por meio da Geja, na condição de executora de tais políticas. As Metas escolhidas versão especificamente sobre formação e valorização dos professores. Outros documentos legais foram utilizados para respaldar as análises propostas.

A pesquisa é relevante, pois alimenta as discussões existentes no contexto educacional brasileiro sobre a EJA e se estabelece como um marco, pois é genuína na área de atuação da esfera municipal do Rio de Janeiro. Traz a compreensão da lógica que sustenta as políticas de formação e valorização dos professores do Peja por dentro do próprio "sistema". A pesquisa também oportuniza um espaço de escuta coletiva e reflexões sobre as realidades vividas pelos professores da EJA, servindo de instrumento de resistência e luta para todo o País. 


\section{METODOLOGIA}

Campo da Pesquisa: O município do Rio de Janeiro tem uma área de $1.197,463 \mathrm{~km}^{2}$ e 6.453 .682 habitantes, segundo o IBGE/2014.

Figura 1 - Mapa do Município do Rio de Janeiro dividido em onze CREs

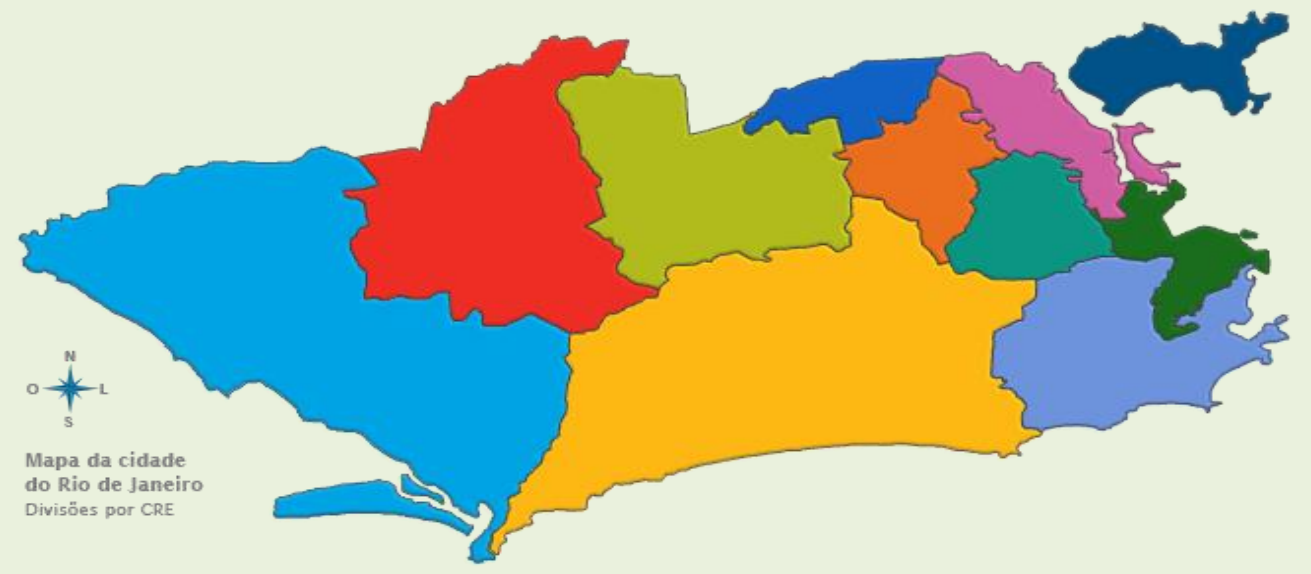

Fonte: Plataforma digital da Prefeitura Municipal do Rio de Janeiro.

Cerca de $95,8 \%$ da sua população são alfabetizados. Segundo dados da plataforma digital da Prefeitura Municipal do Rio de Janeiro 4, existem na atualidade, 1.524 escolas e mais 160 creches conveniadas. Entre essas escolas, 133 funcionam com Peja.

Agentes da pesquisa: 14 no total. Onze professores Acompanhantes de Peja (um por CRE) e mais outros três integrantes da Geja: um gerente e dois adjuntos.

Procedimentos da pesquisa - instrumentos de produção de dados e análises: entrevistas semiestruturadas com os agentes da pesquisa. Aplicação de questionário objetivo, apenas para os Acompanhantes de Peja (Survey com 22 questões), obedecendo a escala Linkert de 7 pontos, que proporcionou após tabulação, gerar gráficos, quadros e tabelas; Análise de Documentos: PNE (metas 15, 16, 17 e 18); LDB no 9.394-96; Diretrizes Curriculares Nacionais; Constituição Federal/88; Circulares internas do município voltadas ao PEJA; Observatório do PNE.

4 Disponível em: http://www.rio.rj.gov.br/web/sme/educacao-em-numeros. Acesso em 20.10.2016, às $23 \mathrm{~h} 55 \mathrm{~min}$. 
Desta forma a pesquisa seguiu o viés qualitativo por ser coerente com o entendimento de que o conhecimento é uma construção coletiva, portanto, parte da realidade dos sujeitos, mediados por processos de reflexão e desvelamento da realidade estudada, conforme esclareceu Minayo (2001). Exploratória, por se tratar de assunto inédito no município. O método fundante foi o Materialismo Histórico-Dialético, corrente filosófica que instituiu uma nova dialética, que parte do conceito basal de que o mundo não pode ser considerado um complexo de coisas acabadas, mas sim, um processo de coisas complexas (SANFELICE, 2008). E as análises de conteúdo contemplada recaíram sobre os procedimentos criados por Bardin (2006).

[..] um conjunto de técnicas de análise das comunicações, que utiliza procedimentos sistemáticos e objetivos de descrição do conteúdo das mensagens. ... A intenção da análise de conteúdo é a inferência de conhecimentos relativos às condições de produção, inferência esta que recorre a indicadores (p. 38).

Ełapa importante ao montar e analisar os dados extraídos do campo de pesquisa mediante aos questionários e entrevistas.

O referencial teórico, que deu sustentação central à pesquisa, foi Bourdieu, notadamente nos conceitos de campo, habitus, agente, capital cultural e de violência simbólica. Catani (2015) é um autor que interpreta de forma prática as obras de Bourdieu, portanto, utilizou-se de seu entendimento para condensar os conceitos basilares da pesquisa.

Catani (2015) evidencia a indissociabilidade entre pesquisa teórica e empírica, presente na Sociologia de Bourdieu, bem como para o fato de que "as noções de campo, habitus e capital não podem ser definidas isoladamente, mas apenas no interior do sistema teórico que constituem" (CATANI, 2015 p. 60). O autor ainda chama a atenção para a compreensão do conceito de campo, que viria a substituir o de sociedade, porque pode ser compreendida por um conjunto de microcosmos sociais "dotados de autonomia relativa, com lógicas e possibilidades próprias, específicas, com 
interesses e disputas irredutíveis ao funcionamento de outros campos" (CATANI, 2015 p. 61).

Portanto, os conceitos de habitus e campo, capital cultural e agente e violência simbólica, são imbricados em todas as análises da pesquisadora, possibilitando engendrar uma visão particular das estruturas vinculadas aos agentes, principalmente aos integrantes da Geja e dos Acompanhantes de PEJA. Então, ressalta-se mais uma vez os conceitos justapostos de campo e habitus de Bourdieu (2011):

Os condicionamentos associados a uma classe particular de condições de existência que produzem habitus, sistemas de disposições duráveis e transponíveis estruturas estruturadas (campo), predispostas a funcionar como estruturas estruturantes (habitus), ou seja, como princípios geradores e organizadores de práticas e de representações que podem ser objetivamente adaptadas ao seu objetivo sem supor a intenção consciente de fins e o domínio expresso das operações necessárias para alcançá-los, objetivamente "reguladas" e "regulares" sem em nada ser o produto da obediência a algumas regras e, sendo tudo isso, coletivamente orquestradas sem ser $\mathrm{o}$ produto da ação organizadora de um maestro (p. 87).

Os agentes são possuidores de certos tipos de capital, que se estabelecem por aquisição e sua acumulação por meio de investimentos. Bourdieu (1979) diferencia os três tipos de capital:

El capital cultural puede existir bajo tres formas: en el estado incorporado, es decir, bajo La forma de disposiciones duraderas del organismo; en el estado objetivado, bajo la forma de bienes culturales, cuadros, libros, diccionarios, instrumentos, maquinaria, los cuales son La huella o la realización de teorías o de críticas a dichas teorías, y de problemáticas, etc., y finalmente en el estado institucionalizado, como forma de objetivación muy particular, porque tal como se puede ver con el título escolar, confiere al capital cultural - que supuestamente debe de garantizar - las propiedades totalmente originales (p.11).

A Teoria da Reprodução, baseada no conceito de "violência simbólica", se traduz por uma violência que se exerce com a cumplicidade tácita daqueles que a sofrem e também, frequentemente, daqueles que a exercem na medida em que uns e outros são inconscientes de a "exercerem ou a sofrerem", segundo Bourdieu (1996). Portanto, são formas de coerção 
que se baseiam em acordos não conscientes entre as estruturas objetivas e as estruturas mentais" (BOURDIEU, 2012). Essa acepção conceitual pôde ser observada durante as entrevistas no campo de pesquisa, ajudando a pesquisadora a compor as análises baseadas nos conceitos descritos. Elas se constituíram de:

[...] forma da emoção corporal (vergonha, timidez, ansiedade, culpabilidade), em geral associada à impressão de uma regressão a relações arcaicas, aquelas características da infância e do universo familiar. Tal emoção se revela por manifestações visíveis, como enrubescer, o embaraço verbal, o desajeitamento, o tremor, diversas maneiras de se submeter, mesmo contra a vontade e a contragosto, ao juízo dominante, ou de sentir, por vezes em pleno conflito interior e na "fratura do eu", a cumplicidade subterrânea mantida entre um corpo capaz de desguiar das diretrizes da consciência e da vontade e a violência das censuras inerentes às estruturas sociais (BOURDIEU, 2001, p. 205).

A imposição ideológica constitui-se no aspecto da cultura dominante como cultura geral. O "poder arbitrário" é baseado na divisão da sociedade em classes. Assim, a ação pedagógica ou direcionamento de uma política tende à reprodução da cultura do dominante. O caráter simbólico da violência centra-se nas características fundamentais estrutura de classes da sociedade capitalista, decorrente da divisão social do trabalho, baseada na apropriação diferencial dos meios de produção. Para o êxito desta dominação faz-se necessário ser reproduzida nas mentes dos dominados, a legitimação destas.

Após descrever o modus operandi da pesquisa, vale ressaltar que foram utilizados os protocolos instituídos pela Plataforma Brasil (via Internet), uma vez que a Faculdade de Educação - UFF não possuía Comitê de Ética instituído até o momento da realização da pesquisa.

\section{PROBLEMATIZAÇÃO, DISCUSSÕES E RESULTADOS}

Para se entender como se constitui a valorização e formação continuada dos professores no Brasil, faz-se necessário compreender alguns conceitos e concepções que se encontram no bojo das políticas educacionais. Assim, o primeiro passo é abarcar o entendimento de que a 
política pública é indissociável da relação entre o Estado e a sociedade civil. Boneti (2013), esclarece que:

[...]políticas públicas são ações que nascem do contexto social, mas que passam pela esfera estatal como uma decisão de intervenção pública numa realidade social, quer seja para fazer investimentos ou para uma regulamentação administrativa. Entende-se por políticas públicas o resultado da dinâmica do jogo de forças que se estabelece no âmbito das relações de poder, relações essas constituídas pelos grupos econômicos e políticos, classes sociais e demais organizações da sociedade civil (p. 17-18).

Esse jogo é descrito por Bourdieu, quando correlaciona o campo, o habitus dos agentes e seu capital cultural, onde as relações de poder irão se manifestar na contemplação de algumas políticas em detrimento de outras. Esse jogo também é semântico e na proposição de vocábulos, encontramse intenções subjacentes.

\section{Contextualização da Valorização do Professor}

Assim, passa-se a conceituar o vocábulo "Valorização" do professor. Dialogando com Grochoska (2015), observa-se que o termo é definido por meio de condicionantes:

[...] a valorização do professor é um princípio constitucional que se efetiva por meio de um mecanismo legal chamado carreira, que se desenvolve por meio de três elementos: a) Formação, b) Condições de trabalho e c) Remuneração, tendo como objetivos a qualidade da educação e a qualidade de vida do trabalhador (Reunião Científica) (p.2, grifo da autora).

A valorização do professor está intimamente imbricada com a sua formação profissional, que se estabelece pela formação inicial e formação continuada. A primeira pode ser alcançada por meio dos cursos médio, modalidade normal ou superior nas licenciaturas, habilitando professores para exercerem sua profissão, ela influencia na carreira quando diz respeito ao ingresso e à habilitação; e a segunda se estabelece durante a vida funcional do professor, por meio de cursos de "capacitação" ou de pósgraduação. 
O reconhecimento do valor do professor e a tardia normatização vieram com a Constituição Federal de 1988, reconhecendo a importância da valorização do magistério público como condição para melhorar a qualidade da educação brasileira. Está assegurado no Art. 206. Os seguintes princípios:

$V$ - Valorização dos profissionais de ensino, garantindo, na forma da lei, plano de carreira para o magistério público, com piso salarial profissional e ingresso exclusivamente por concurso público de provas e títulos, assegurado regime jurídico único para todas as instituições mantidas pela União (BRASIL, 1988).

A Lei de Diretrizes e Bases da Educação Nacional (LDB/nº 9.394/96), também reforça a importância da valorização do professor. Assim, o artigo 67 assegura:

Art. $67^{\circ}$ Os sistemas de ensino promoverão a valorização dos profissionais da educação, assegurando-lhes, inclusive nos termos dos estatutos e dos planos de carreira do magistério público: I - ingresso exclusivamente por concurso público de provas e títulos; II aperfeiçoamento profissional continuado, inclusive com licenciamento periódico remunerado para esse fim; III - piso salarial profissional; IV - progressão funcional baseada na titulação ou habilitação, e na avaliação do desempenho; $V$ - período reservado a estudos, planejamento e avaliação, incluído na carga de trabalho; $\mathrm{VI}$ - condições adequadas de trabalho (BRASIL, 1996).

Ainda no Art. $40^{\circ}$ da LDB n 9.394/96, fica estabelecido que os Estados, o Distrito Federal e os Municípios deverão implantar Planos de Carreira e remuneração dos profissionais da educação, de modo a assegurar: I - a remuneração condigna dos profissionais na educação básica da rede pública; II - integração entre trabalho individual e a proposta pedagógica da escola; III - a melhoria da qualidade do ensino aprendizagem.

E o Parágrafo único deixa claro que os Planos de Carreira deverão contemplar capacitação profissional especialmente voltada à formação continuada com vistas à melhoria da qualidade do ensino.

A "condição de trabalho": nesse contexto, a infraestrutura é apenas um condicionante no espaço de trabalho, que se soma à jornada, hora atividade, número de alunos e saúde do trabalhador. Grochoska (2015) 
define como "conjunto de ações que propiciam meios de exercer sua atividade de forma digna, planejada e com qualidade".

A última frente a ser contextualizada é a "remuneração do professor" e se tornam centrais alguns conceitos explicativos:

[...] se faz necessário conceituar três elementos: salário, vencimento e remuneração, pois apresentam bases de cálculo diferentes. Assim, salário é o valor pago pelo empregador ao empregado conforme a Consolidação das Leis de Trabalho (CLT); vencimento é definido pela Lei $\mathrm{n}^{\circ} 8.112$ como "retribuição pecuniária pelo exercício de cargo público, com valor fixado em lei". Assim, tanto salário como vencimento são uma parte da remuneração, que no caso do magistério é composta pelo vencimento mais vantagens pecuniárias, como gratificações, auxílios entre outros (CAMARGO; JACOMINI, 2010, p.23).

Assim deve-se compreender por remuneração do professor, a espécie monetária que ele recebe, contando gratificações e abonos; e vencimento, que por sua vez se desdobram em: vencimento e a progressão na carreira.

No cenário educacional, existe uma vertente de pensadores, que culpabilizam os professores pelos malogros resultados da educação brasileira. Não se pode generalizar os maus profissionais, por isso, faz-se necessário vigorar o sistema avaliativo, conforme já estabelecido na Resolução/CNE $n^{\circ} 2$ de 2015, no artigo 19, que prime por impulsionar e motivar os professores a se envolverem com a comunidade, a buscarem melhores formações continuadas e em contrapartida serem valorizados pelos seus esforços. Um sistema avaliativo agregador de valores e não punitivo ou ranqueador.

\section{Reflexões sobre formação continuada}

A formação continuada passa a ser uma política redentora para ajudar a reverter esse quadro de descrédito e má formação dos professores em exercício. Não se exime a responsabilidade das instituições responsáveis pela formação inicial, mas mediante a um quadro já estabelecido, faz-se necessário suprir deficiências dos docentes que já atuam em salas de aula. 
A Lei de Diretrizes e Bases da Educação Nacional, Lei n 9.394, de 1996, no seu artigo 62, estabelece dois fundamentos para a formação dos professores, quais sejam: a associação entre teorias e práticas, incluindo aí a capacitação em serviço; e o aproveitamento da formação e experiências anteriores em instituições de ensino e outras atividades. O artigo 62 estabelece os centros formadores e a responsabilidade dos entes federados, assim como as formas de formação continuada. Há que se evidenciar a necessidade de formação de todos os profissionais da educação. Compreender o sentido global e integrado das políticas.

Após refletir dialeticamente sobre as políticas de formação e valorização dos professores brasileiros, passa-se a contextualizar a história da EJA no País e do Peja no município do Rio de Janeiro, buscando correlacionar a situação atual da formação e valorização dos professores do Peja, com as Metas 15, 16, 17 e 18, estipuladas pelo PNE e fomentadas pela Geja-RJ.

\section{Percalços da EJA e surgimento do Peja no Município do Rio de Janeiro}

A história da educação de jovens e adultos no Brasil é recente, pois essa preocupação só iniciou de fato, após os anos 1930, com a necessidade de mão-de-obra mais "qualificada operacionalmente", para atender ao mercado de trabalho (BEISIEGEL, 2003). Então, para atender os moldes de produção capitalista, a educação passou a assumir dimensões de campanhas, não havia preocupação com a formação dos professores, podendo assumir a função, qualquer pessoa com conhecimentos básicos.

A partir de 1964, esses movimentos foram paralisados e substituídos pela ala conservadora da política brasileira Cruzada $A B C$ e o Movimento Brasileiro de Alfabetização (Mobral). Inicia-se uma nova etapa funesta do histórico da EJA, conforme Paiva, Machado e Ireland (1973). O Mobral, criado em 1967, só vigorou em 1970, a partir da LDB n 5.692/71. Foi uma política educacional descompassada e distante da educação emancipatória proposta por Paulo Freire 
Com os pífios resultados do Mobral e a pressão da sociedade por uma educação efetiva e crítica, em 1985, este deixa de existir e é substituído pela Fundação Educar, que era responsável por articular o ensino supletivo e a política nacional de EJA, além de fomentar o atendimento nas primeiras séries do $1^{\circ} \mathrm{grau}$. Almejava em médio a longo prazo, erradicar ou reduzir drasticamente o analfabetismo no País, a partir do modelo administrativo da antiga Fundação Mobral, portanto, nada mudara. Era a gestão do presidente José Sarney. Com a entrada de Collor na presidência, foi extinta a Fundação Educar em 1990, através da medida Provisória nº 251.

Em 1997, o governo Federal monta o Programa Alfabetização Solidária, em parceria com MEC e a sociedade civil. Por seu caráter assistencialista e aligeirado (alfabetização em seis meses), foi dado ao insucesso, conforme analisado por Beisiegel (2003).

Importante acrescentar que, nessa época, a América Latina estava assentando as políticas sociais compensatórias neoliberais, que tinham em seu escopo o enfoque da descentralização e da privatização, adaptadas às características nacionais (DI PIERRO, 2010). Ficam claros os interesses econômicos das forças dominantes na sociedade, que lucram com o insucesso do Estado ao se apresentarem como solução para a crise educacional.

Embora a Constituição de 1988 garanta a Educação para todos os cidadãos, o direito não passou de direito formal, ou seja, garantido em leis que não se estabelecem na prática. Soma-se à Constituição Federal: a LDB $n^{\circ}$ 9.394/96 nos artigos 37 e 38 e o Parecer CNE/CEB n 11/2000. Esses textos legais reafirmam a educação como direito público subjetivo, mas sua eficácia está por vir. Após contextualizar sinteticamente a história da EJA no País, passa-se a discorrer sobre a origem do Peja.

A história do Peja inicia-se no ano de 1984, criado em três escolas do município carioca. Esta proposta foi encampada pelo Projeto de Educação Juvenil, no ano seguinte, em 1985, fazia parte de outro programa maior, conhecido como Programa Especial de Educação (PEE). Foi elaborado por Darcy Ribeiro, professor e também vice-governador, junto com Leonel 
Brizola, no Rio de Janeiro (1982-1986). Iniciou-se com vinte Centros Integrados de Educação Pública (CIEPs). E foi idealizado para atender à população de quinze a vinte anos analfabeta. A proposta pedagógica era baseada na "perspectiva cidadã" e na concepção de Paulo Freire.

Na atualidade, as escolas que funcionam com a modalidade da EJA no município do Rio de Janeiro estão espalhadas pelas 11 CREs e somam 133 unidades escolares. O Peja atende jovens, adultos e idosos a partir de 15 anos de idade e se constitui de duas grandes etapas, conforme o quadro abaixo:

Quadro 1 - Peja I e Peja II

\begin{tabular}{|c|c|}
\hline Peja I & Peja II \\
\hline $\begin{array}{c}\text { BLOCO I (corresponde: } \\
\text { Alfabetização, } 1^{\circ} \text { e } 2^{\circ} \text { ano do EF } \\
\text { regular) }\end{array}$ & $\begin{array}{c}\text { BLOCO I (corresponde: } 6^{\circ}, 7^{\circ} \text { anos } \\
\text { do EF regular) }\end{array}$ \\
\hline $\begin{array}{c}\text { BLOCO II (corresponde: } 3^{\circ}, 4^{\circ} \text { e } 5^{\circ} \\
\text { anos do EF regular) }\end{array}$ & $\begin{array}{c}\text { BLOCO II (corresponde: } 8^{\circ} \text { e } 9^{\circ} \text { anos } \\
\text { do EF regular) }\end{array}$ \\
\hline
\end{tabular}

Fonte: OS autores, a partir do Parecer 06/2005.

Somente em 2005, que o PEJ, passou se chamar (Peja). Os primeiros professores participantes desse Projeto eram os próprios professores municipais concursados. Eles eram convidados e havia encontros regulares que serviam como capacitações. Essa sistemática ainda vigora na atualidade, embora tenha sofrido alterações bastante questionáveis, pelos próprios agentes da pesquisa. Pois hoje, os professores continuam sendo convidados por meio de uma requisição feita pelos diretores das escolas de Peja, que mediante a um discurso falacioso, selecionam professores, muitas das vezes amigos, que detém o "Perfil" adequado para trabalhar com os alunos do Peja. Um julgamento subjetivo sem um critério formal e confiável.

Segue alguns extratos da pesquisa, dos agentes Acompanhantes de Peja, para o seguinte questionamento da pesquisadora: Quais ações você sugere para ajudar na formação dos professores do Peja, e consequentemente no desenvolvimento dos alunos do Peja? Concurso 
público para essa modalidade pode ser uma boa política para formar os quadros de professores do Peja?

\begin{abstract}
"[..] mais encontros com trocas de experiências e licença para fazermos cursos de pós-graduação na nossa área. Quanto ao concurso...não sei responder, a proposta atual ficaria descaracterizada, mas por outro lado já estamos descaracterizando com a entrada de professores $40 \mathrm{~h}$ em concursos e acomodações funcionais...Talvez...

"Acho que o concurso não iria ser a solução (pausa para pensar), apesar de que hoje em dia não se recorre mais aos bancos de inscrições, o diretor que indica e também agora temos a questão dos professores de $40 \mathrm{~h}$ que estão chegando, então não sei... por outro lado poderia legitimar e também normatizar a EJA, porque os professores vivem com medo de acabar essa modalidade. Qualquer coisa, se fala em fechar turmas e o professor tem medo de ficar sem aquela unidade de trabalho".

"Creio que o concurso fosse moralizar a entrada de professores, que por muitas vezes pensam em ir para o Peja para se livrar dos gritos das crianças, das correções de provas e assim trabalhar menos".
\end{abstract}

Observa-se na análise das falas um direcionamento para que ocorra a política de contratação, via concurso público e que seja mais recorrente as capacitações por meio de trocas de experiências e licenças para estudos.

A mesma proposição foi feita para os gestores da Geja, que disseram ser o processo em prática, um critério subjetivo e que na realidade não existem características pré-estabelecidas em lei, mas que deveriam gostar de trabalhar com jovens e adultos e compreender as necessidades destes alunos.

Questionados sobre o atual critério de seleção, disseram que esperavam que os diretores fossem criteriosos, mas que sabiam que existem professores sem o compromisso necessário, assim como diretores que contemplam profissionais amigos.

Caldeira e Caluzzi (2003) trazem uma importante contribuição à análise aqui desenvolvida, explicando que o processo de construção da identidade docente não é algo estático, mas sim, dinâmico, e se vincula a uma permanente construção, desconstrução e reconstrução de seus elementos, o que demanda redefinições constantes, dependendo do 
contexto sociocultural em que os sujeitos se encontram. Portanto, é no processo que o dito "Perfil" vai sendo construído, então, a proposta de concurso público como meio de acesso constitui-se como política mais adequada, porque minimamente garante que os concursados saibam a teoria necessária para lidar com as especificidades dos alunos do Peja. Segue a citação de Soares (2011), que respalda a política de contratação via concurso público.

[...] entre os desafios a serem enfrentados na formulação de políticas públicas encontra-se a profissionalização dos educadores. A falta de concurso público direcionado à EJA contribui para que o campo reproduza o amadorismo e o improviso no enfrentamento de suas questões (p. 315).

Desta forma, fica claro a necessidade de se rever a política de seleção dos professores do Peja como forma de contribuir com a melhoria da educação ofertada pelo município do Rio de Janeiro.

Importante compreender o espectro da Geja na macroestrutura da Secretaria Municipal de Educação (SME- RJ). A organização funcional é complexa, são oito gerências ligadas à Coordenadoria de Educação, dentre essas, a Geja. Responsável por administrar todos os assuntos ligados ao Peja, possui um braço ou satélite de subordinação, diretamente vinculada a ela, o Centro de Referência de Educação de Jovens e Adultos (Creja).

O Creja foi criado em 2004, localizado no centro comercial da cidade. Entre suas funções, é responsabilidade oferecer formação continuada aos professores do Peja, atender um maior contingente de alunos trabalhadores da área central. A proposta de trabalho é baseada em módulos, além de ser diretamente responsável pelo Ensino à Distância (EaD). Os extratos abaixo mostram a percepção dos Agentes da pesquisa com relação ao funcionamento do Creja.

Quando feita a pergunta: O que sugere como pontos a serem revistos na formação e valorização dos professores do Peja? e O Creja auxilia na formação dos professores? 
"foi criado para ser um Centro de Referência, mas trabalha descolado do Peja, pois a proposta de trabalho é completamente diferente da aplicada no Peja. Deveria ser um centro de capacitações para diferentes assuntos ligados à EJA";

"deveríamos ter um Centro de Referências que se ocupasse de pesquisas na área, pois a Creja que existe, não funciona como referência, pelo contrário, é uma proposta de trabalho completamente diferente das CREs. Deveria ser a finalidade deste Centro de referência da EJA";

"a Creja é um centro de referência e se coloca à disposição da Geja, mas tem ocorrido pouco intervenções desse Centro, que poderia ajudar, de repente, mais nas capacitações de professores";

"o Creja deveria ser um Centro de Referência para as outras CREs, mas tem uma proposta diferenciada da Rede e não serve como um polo de apoio e pesquisa como é o caso da Escola Paulo Freire (...) Deveria ser melhor gerenciada com esse propósito".

Observa-se pelas falas dos agentes da pesquisa, que o Creja precisa passar por uma análise crítica de suas funções e desta forma, fazer valer o nome de Centro de Referência da Educação do Jovens e Adultos. Que pese nessas falas a responsabilidade da Geja, esta deve articular diretrizes com o pessoal do Creja de forma que venha saber e promover, ações formativas para seus professores.

A tabela abaixo mostra o nível educacional dos professores do PejaRJ. Importante ressaltar que os integrantes da Geja não tinham o conhecimento formativo sobre seus professores até a data da pesquisa. Os dados foram elaborados a partir de solicitação da pesquisadora à Gerência de Recursos Humanos da SME- RJ.

Tabela 1 - Formação dos professores do PEJA

\begin{tabular}{lr}
\hline Doutorado & 6 \\
Médio especializado & 83 \\
Mestrado & 75 \\
Pós-doutorado & 1 \\
Pós-graduação & 160 \\
Superior & 790 \\
Superior incompleto & 19 \\
\hline Total Geral & 1.134 \\
\hline
\end{tabular}

Fonte: SME RJ - outubro de 2017. 
Os dados indicam que a formação dos professores do Peja-RJ não atende a Meta 15. Esta meta, estabeleceu dois anos após a sanção do PNE, (Julho/2014), como data limite para que todos os professores em exercício, possuíssem o nível Superior completo. Mas o que se observa na formação dos professores do Peja, é que dos 1.134 deles, 102 ou 9\%, não possuem o nível Superior completo, exigido pela Lei. São 83 professores com apenas o nível Médio especializado e 19 outros, com curso Superior incompleto.

A Meta 16, que prevê formação de $50 \%$ dos professores, em nível de pós-graduação até o final da vigência do Plano, em 2024, é possível ser cumprida, pois 242 professores, correspondendo a $21,35 \%$, já possuem a formação desejada. Embora seja necessário maiores incentivos, pois faltam ainda $28,65 \%$ do demais professores concluírem a formação adequada para atender a essa Meta.

A Meta 17 que prevê a equiparação do rendimento médio dos professores com os demais profissionais de escolaridade equivalente, se mostra coerente com o que é estipulado pelo PNE. O valor pago da hora/aula do professor, hoje no município é um dos mais altos, dentro do estado. Após uma greve expressiva em 2013, foi acordado com o então Prefeito Eduardo Paes, que seria corrigido a distorção entre os docentes com a mesma formação, no prazo de 5 anos, ou seja 2018.

A Meta 18 que estabelece a criação e regulamentação do Plano de Cargos, Salário e Carreira do Magistério, vigora no Município, porém, apresenta distorções gritantes que estão em processo de ajustes. Somente os professores com carga horária de 40h, tinham o direito de enquadramento por formação da Pós-graduação Lato Sensu, Doutorado e Pós-doutorado.

Respondendo ao primeiro objetivo específico da pesquisa, pode-se afirmar que a equipe monta suas ações mediante a uma limitação financeira, que no ano de 2017, foi da ordem de pouco mais de 500 mil, praticamente paralisante mediante ao universo de 133 escolas e 1.134 professores de Peja e principalmente em virtude das elevadas obrigações com o Creja (Contas altas de energia e manutenção de equipamentos, para o bom funcionamento do Centro), sobrando uma pequena verba para 
organização de cursos, palestras, colóquios entre outras políticas com objetivo formativo dos professores.

A Geja atualmente mobiliza colaboradores palestrantes da Rede e fora dela, que participam gratuitamente de eventos diversos, que envolvam algum tipo de formação programada e continuada para os professores do Peja sem que tenha que pagar por esses trabalhos. Uma prática usual, que evita confronto com chefias acima de sua estrutura funcional, já que a verba é escassa, ocorrendo pagamento para palestrantes em raras ocasiões. O capital cultural dos integrantes da Geja, possibilita que haja harmonia entre a precariedade dos recursos oferecidos pela SME-RJ e os meios para se atingir os fins.

No segundo objetivo específico foi possível compreender que inexiste um mecanismo unificado nas 11 CREs referente às normas de requisição dos professores do Peja. Não existe concurso público para essa modalidade no Município. A sistemática atual de ingresso constitui-se na prática de indicação dos Diretores de escolas de Peja, que escolhem os professores mediante o chamado "Perfil de professor de Peja", que na prática constituise de "clientelismo" de muitos Diretores de escolas do Peja.

Já é tempo de quebrar esse paradigma que concentra o poder decisório dos Diretores de escolas de Peja, até porque, como diz Nóvoa (1992, p.25) "a formação [...] se constrói através de um trabalho de flexibilidade crítica sobre as práticas e de (re)construção permanente de uma identidade pessoal". O que Bourdieu chamaria de experiências capitalizadas, ou seja, o perfil ou personalidade identitária se estabelece nas ações diárias, no trabalho com os alunos do Peja, assim a proposta do concurso público se mostra mais apropriada, pois garante que todos os aprovados tenham conhecimento teórico sobre o universo da EJA, enquanto a sua identidade prática estará sendo formada entre cursos, seminários e ações pedagógicas compartilhadas entre seus pares no universo trabalhado. 
A Prefeitura do Rio de Janeiro, realiza hoje em dia, concurso setorial para todas as modalidades de ensino sob sua responsabilidade, faltando estender a política para o Peja.

O terceiro objetivo teve nas entrevistas dos agentes, o suporte para o entendimento dos efeitos das políticas implantadas pela Geja, por meio das percepções destes, mediante a descrição da dinâmica vivenciada no PejaRJ. Assim foi possível compreender que não existe uma preocupação efetiva em vincular a Lei, nesse caso o PNE, às ações propostas aos professores. Fazse justo evidenciar o trabalho que a Geja, estava realizando com uma doutora da Uerj em alfabetização, mapeando quinze escolas com problemas na área, para intervenções futuras. Um projeto que se encontrava em andamento no ato das entrevistas (agosto de 2017). Há trabalhos importantes sendo feitos, porém são pontuais e tímidos mediante a demanda existente a ser contemplada.

A percepção geral dos Acompanhantes de Peja com relação ao trabalho desenvolvido pela equipe da Geja é positiva, conforme gráfico abaixo, mas que deve ser analisado a luz de Bourdieu. A média se estabelece em torno de 5,82\%. Uma assertiva de $83 \%$, confirmando uma positividade das ações.

Grafico 1 - Valiação do desempenho da GEJA



Fonte: Os autores, com base em dados colhidos ementrevistas 
A equipe tem bons propósitos e dentro da estrutura, estruturante, utilizando o entendimento de Bourdieu, cumpre seus propósitos. Porém há que interpretar o gráfico de forma interligada com as entrevistas e todo o conjunto de percepções, do corpo, da fala e trejeitos. Porque as vozes destes agentes, em outras proposições, já apontavam falta de efetividade das políticas de formação dos professores, principalmente do Creja.

Os agentes, analisam as relações, contrabalançando os prós e contras, levando em consideração o trato pessoal, as condições financeiras disponíveis pela Geja, o empenho dos professores, dimensão do espaço territorial do Município e outros condicionantes, portanto, tendem a minimizar o impacto da realidade, descrito pelo conceito de violência simbólica. Contudo, não se tira o valor da equipe.

O quarto objetivo concentra-se em compreender os parâmetros pela qual a Geja, avalia as políticas de formação continuada e valorização implementadas por ela, tendo como norteador o PNE. Pode-se concluir que essa avaliação é restrita e informal, porque prioriza a capacidade substantiva sem maiores utilizações com os dados recolhidos ou que se vincule as Metas do PNE.

Há um canal de escuta aberto em todas as ações propostas para os professores, quer sejam nos cursos oferecidos, seminários, entre outras ações. Portanto, é dada a possibilidade dos participantes se colocarem perante o trabalho oferecido. Mas falta um melhor tratamento dos dados, de modo que sirvam de bases para outras políticas de correção e/ou afirmação.

Há necessidade de um mecanismo de avaliação de larga escala, que priorize a capacidade técnica ou quantitativa das ações realizadas pela Geja, que ajude a inferir os ganhos com as ações implementadas por ela. Os próprios conceitos dos alunos poderiam ser indicadores potentes se fossem usados e retratassem a realidade dos alunos, pois foi revelado pelas entrevistas, que o Sistema Gerencial Acadêmico do Peja, é falho, não é confiável. Um assunto sério que é sabido pela Geja, mas ainda não resolvido junto a outros órgãos da SME. 
Durante a pesquisa, muitas questões foram sendo atravessadas aos objetivos da Tese, as quais importam serem elencadas. O currículo do Peja, principalmente com a entrada das novas tecnologias, foi uma das questões levantadas como necessidade de adequações para que se consiga auxiliar os alunos do século XXI, assim como capacitar os professores para utilizarem as mídias.

Há necessidade que o Instituto Helena Antipofe (IHA) trabalhe mais próximo dos professores, auxiliando no trato com os alunos portadores de deficiências. O IHA é o setor responsável pelo Ensino Especial no município, cabendo capacitar os professores para estarem melhor preparados para lidar com os alunos com deficiências.

Quanto à questão da valorização dos professores, a Geja reconhece o valor dos docentes, mas a sua valorização é restringida em virtude de seu poder administrativo. Já a SME, responsável majoritária pelas políticas de valorização de todos os professores do Município, estipulou inúmeros benefícios descritos em leis e decretos, tais como: auxílio transporte, auxílio creche, convênio com plano de saúde, "licença para estudo", entre outros. Pode-se dizer que há valorização nesse sentido, porém, a licença para estudar precisa ser um processo acessível de fato, devendo ser restringida à burocracia.

\section{CONSIDERAÇÕES FINAIS}

Ainda que o trabalho da Gerência de Educação de Jovens e Adultos seja reconhecido unanimemente pelos professores Acompanhantes de Peja, como responsável e que, a equipe da Geja, se mostre engajada em realizar tarefas que the são pertinentes, muito precisa-se fazer para impulsionar a formação continuada dos professores do Peja e consequentemente valorizar seus professores. Dos 1.134 professores, 102 deles não possuem o nível superior completo, exigido na Meta 15. Estes correspondem a $9 \%$ do efetivo de professores. O tempo para se cumprir esta etapa já expirou e a Geja, não tinha o conhecimento real da formação de seus professores até o momento 
das entrevistas, em agosto de 2017. Não se pode propor ações formativas, sem que se saiba quem precisa e do que precisa.

A Meta 16, que prevê formação de $50 \%$ dos professores, em nível de pós-graduação até o final da vigência do Plano, em 2024, pode ser cumprida, pois 242 professores, correspondendo a 21,35\%, já possuem a formação desejada, incluindo nesse percentual, pós-doutores, doutores, mestres e pós-graduados em nível lato sensu, portanto, ainda falta para o cumprimento da Meta, 28,65\%, no intervalo de seis anos. Não será fácil de cumprir, caso não sejam aprovados alguns PLs, que seguem tramitando na Câmara dos Vereadores. Principalmente O PL (589/2017), que visa corrigir erros grosseiros na elaboração do (PCCR), onde foram marginalizados os professores: PI 16h, PI 30h, Pll 22,5h e PEl 22,5h da possibilidade de enquadramento de pós-graduação lato sensu, mestrado, doutorado e pósdoutorado. A Geja, deve buscar diálogo junto à SME, criando oportunidades para seus professores se especializarem.

A Meta 17, que prevê a equiparação do rendimento médio dos professores e demais profissionais com escolaridade equivalente, até o final do $6^{\circ}$ ano da vigência do PNE mostra-se coerente com o nível salarial dos professores atuais, do Município. Lembrando que, para que todos os professores atingissem o mesmo valor hora/aula, foi necessário luta da categoria, que resultou em ajuste parcelado em cinco anos (2013-2018).

A Meta 18 que estabelece a criação e regulamentação do Plano de Cargos, Salário e Carreira do Magistério, existe no Município, embora o mesmo apresente distorções gritantes a serem sanadas. Os docentes de regime de trabalho de $40 \mathrm{~h}$ recebem vários benefícios, que não são oferecidos proporcionalmente para os demais professores com regime de carga horária diferente. Ainda analisando O PCCR, compreendendo a maneira pela qual o professor do Peja e demais professores do Município vêm sendo tratados, observa-se que os ganhos, mediante o nível por tempo de serviço e por formação, são de $4 \%$, irrisórios quando comparados a esfera estadual e federal. A duração em média de cinco anos para cada nível é longa e são apenas sete níveis no total. O ganho de um professor ao realizar 
o mestrado é de $12 \%$ e se obtiver o doutorado, ganhará mais $3 \%$ não cumulativos.

As demais etapas formativas, não são contempladas ainda hoje no Município (abri/2019), que reconhece o benefício, mas não cumpre a lei do PCCR. O valor do doutorado será $2,67 \%$ em cima do valor do mestrado, ou se entrar com o enquadramento direto com a formação de doutor, receberá 15\%. O professor que realiza o pós-doutorado terá aumento de $5,217 \%$ sobre o valor do doutorado. O percentual total por formação até o Pós-doutorado soma-se no total $21 \%$. Além dos objetivos analisados, outros questionamentos atravessaram o campo analisado. Assim, pode-se elencar os principais pontos nevrálgicos que emergiram do campo de pesquisa e que devem ser sanados pela Geja/SME/RJ:

a- O IHA precisa estar mais próximo da Geja, realizando um trabalho de parceria que ajude na formação dos professores para lidarem com os alunos incluídos, cabendo à Geja, buscar essa colaboração e acompanhar;

b- O Creja precisa ser um centro de referência de fato e agregar valores às propostas do Peja, com cursos de formação para professores e pesquisas voltadas a área que ajudem a lidar com os problemas que são recorrentes na EJA;

c- Parcerias com as Universidades com cursos de Pós-Graduação ligados a EJA e com licença para os professores realizarem. Cabe à Geja, buscar dialogar com as Universidades previamente e estudarem maneiras de se oferecer cursos presenciais e à distância que ajudem na formação continuada dos professores;

d- Lutar junto a SME para que haja isonomia salarial por formação. Valorização de todos os professores, maior ganho percentual por nível de formação e tempo de serviço, maior ganho para os cursos de mestrado e doutorado, pós-doutorado;

e- Buscar legalmente a reformulação do currículo da EJA com introdução de oficinas na grade curricular, incluindo, Artes, EF, Informática, Sala de Leitura e Língua Estrangeira para os Blocos I e II. Uma proposta que se molde às necessidades dos alunos deste século e seja unificada, pois hoje não há um 
currículo igualitário para todas as escolas do Município (embora essa questão não verse diretamente sobre a questão de pesquisa, apareceu como forte sugestão a ser implantada e como possível solução para se adequar a grade curricular com as necessidades dos alunos do século XXI, evitar a evasão dos alunos e desta forma tornar a escola atrativa);

f- Centros de Estudos devem ser usados para a formação de professores com assuntos selecionados pelos professores de cada escola e a Professora Orientadora ( $\mathrm{PO}$ ) deve dinamizar os estudos, criando-se uma cultura dos estudos e pesquisa para melhorar a formação continuada em serviço, inclusive com cursos de informática para os professores poderem lidar com as mídias atuais.

Ressaltando os ensinamentos de Pierre Bourdieu, que reconhece a escola como instituição fundamental no processo de reprodução social, ao simular as condições em que esse processo acontece, contribuindo como instrumento ideológico de dominação e naturalização, portanto, assegurando o caráter reprodutivista, são revelados nesta pesquisa alguns mecanismos de manutenção desse processo por meio da formação continuada deficitária. Na valorização do professor do Peja-RJ, assim como algumas possibilidades de transformação social descritas há muitas questões a serem repensadas, edificadas, modificadas, instituídas e reafirmadas, para que, a função transformadora da escola como princípio do conhecimento e condição primeira, torne-se instrumento fundamental de modificação social.

O habitus dos agentes reflete o contexto (campo) em que ele foi formado e tende a gerar uma situação, onde este o entende como única realidade possível, direcionando suas ideias e suas ações à manutenção da ordem social, sem que o agente questione e busque compreender as contradições inerentes à estrutura. Portanto, quanto mais momentos de reflexões entre os professores se possa oportunizar, maiores serão suas percepções coletivas e maiores os ganhos entre as experiências compartilhadas.

Desta forma, poderão ocorrer transformações sociais nas salas de aula, pois o professor ao melhorar sua formação, proporcionará uma melhor aula 
aos alunos. Ainda, relembrando Bourdieu, a escola tem uma autonomia relativa, podendo ser palco de transformações sociais e não apenas de sua reprodução, vinculados pela violência simbólica, retratada pelo sistema capitalista. Emergem as possibilidades de pensar e fazer por meio do próprio sistema escolar, necessitando que seus agentes tenham o compromisso social.

Nesse processo, a ação do professor como agente é fundamental, precisando estar mais formado e ser valorizado, cabendo à Geja, como equipe formada por agentes sociais, ultrapassar as barreiras do conformismo e estagnação dessa estrutura social bem montada, que se estabelece de maneira sutil e jamais desinteressada (SME-RJ), que conduz ao recrudescimento das ações políticas, encontrar brechas e utilizando estratégias para que seu gerenciamento possa se estabelecer como ponto de resistência e caminhos à equidade social do Peja-RJ.

Essas situações e outras descritas na pesquisa levam a dizer que tanto a formação continuada, quanto a valorização dos professores do Peja premem por se constituírem de forma mais efetiva, embora possam apontar pontos positivos tanto na formação, quanto na valorização dos professores do Peja e dos demais professores da Rede.

Portanto, pode-se concluir que a responsabilidade é de todos os agentes e instituições, cabendo à GEJA, esforçar-se para atender as Metas que se encontram sob sua alçada, implantando uma nova cultura de corresponsabilidades entre seus parceiros e, principalmente, intensificando cursos de formação continuada de acordo com a formação e necessidades de seus professores. Assim, é importante conhecer a fundo os problemas de cada CRE e criar um plano de ação que contemple implantar e avaliar melhor suas ações e direcionar melhor o Creja.

Então, para finalizar as considerações, sugere-se novas pesquisas no campo da EJA, quer sejam em relação aos métodos de alfabetização utilizados pelos professores; quer seja na compreensão e alcance do IHA no município do Rio de Janeiro; quer pelo estudo do currículo da EJA ou ainda sobre os trabalhos e responsabilidades das IES com a formação dos 
professores. Desta forma, acredita-se ter contribuído com o PEJA-RJ, apontando direcionamentos importantes que podem ser refletidos em todo o País.

\section{REFERÊNCIAS}

BARDIN, L. Análise de conteúdo (L. de A. Rego \& A. Pinheiro, Trads.). Lisboa: Edições 70. (Obra original publicada em 1977) 2006.

BEISIEGEL, C. de R. A educação de jovens e adultos analfabetos no Brasil. Alfabetização e Cidadania, São Paulo, v. 16, p. 19-27, 2003.

BONETI, L. W. As políticas públicas no contexto do capitalismo globalizado: da razão moderna à insurgência de processos e agentes sociais novos. PRACS: Revista Eletrônica de Humanidades do Curso de Ciências Sociais da UNIFAP, v. 5, n. 5, p. 17-18, 2013.

BOURDIEU, P. Sur la televisión; suivi de l'emprise du journalisme. Paris: Raisons d'Agir, 1996.

BOURDIEU, P. Meditações pascalianas. Rio de Janeiro: Bertrand Brasil, 2001. p.205

BOURDIEU, P. Capital cultural, escuela y espacio social. Buenos Aires: Siglo Veintiuno, 2012.

BOURDIEU, P. (A) Economia das trocas simbólicas. 5. ed., São Paulo: Perspectiva, 2011 . p.87.

BOURDIEU, P. Los Tres Estados del Capital Cultural, en Sociológica, UAMAzcapotzalco, México, n 5, p. 11-17, 1979.P.11.

BRASIL. Plano Nacional de Educação 2014-2024. Lei nº 13.005, de 25 de junho de 2014a. Disponível em < http://www.planalto.gov.br/ccivil_03/_ato201 12014/2014/lei/l13005.htm> Acesso em 06 de abril de 2016.

BRASIL. Presidência da República. Lei n 9.394, de 20 de dezembro de 1996. Estabelece as diretrizes e bases da educação nacional. Brasília: 20 de dezembro de 1996. Disponível em:< www.planalto.gov.br/ccivil_03/LEIS/19394.htm> Acesso em 07.12.2014.

BRASIL. Presidência da República. Constituição da República Federativa do Brasil. Brasília, 1988. Disponível em:www.planalto.gov.br/ccivil_03/constituicao/constitui \%C3\%A7ao.htm. Acesso em 07.10.2016. 
BRASIL. Lei 12796, de 4 de abril de 2013. Altera a Lei 9394 de 20 de dezembro de 1996, que estabelece as diretrizes e bases da educação nacional, para dispor sobrer a formação dos profissionais da educação e dar outras providências.

BRASIL. Rio de Janeiro. Projeto de Lei Municipal, PL 589 de 20217. Define as funções de magistério (função gratificada é função de magistério).

BRASIL. Lei № 5.692, de 11 de agosto de 1971. Fixa Diretrizes e Bases para o ensino de $1^{\circ}$ e $2^{\circ}$ graus, e dá outras providências.

BRASIL. IBGE. PNAD. 2014.

BRASIL. Decreto $n^{\circ}$ 62.455, de 22 de março de 1968. Mobral.

CALDEIRA A.; CALUZI J.J, organizadores. 2003. Filosofia e História da Ciência: contribuições para o ensino de ciência. Ribeirão Preto: Kayros.

CAMARGO, R. B.; JACOMINI, M. A. Carreira e salário do pessoal docente da educação básica: algumas demarcações legais. 2010, p. 23.

CAPUCHO, V. Educação de jovens e adultos: prática pedagógica e fortalecimento da cidadania. São Paulo: Cortez, 2012.

CATANI, A. M. Origem e destino: pensando a sociologia reflexiva de Bourdieu. Campinas: Mercado de Letras, 2015. p.60 - 61.

DI PIERRO, M. C. A educação de jovens e adultos no Plano Nacional de Educação: avaliação, desafios e perspectivas. Educação \& Sociedade, setembro de 2010, Vol.31(112), p.939-959.

GROCHOSKA, M.A. Políticas educacionais e a valorização do professor: carreira e qualidade de vida dos professores de educação básica do município de São José dos Pinhais/PR. 269f. Tese (Doutorado em Educação). Universidade Federal do Paraná, Curitiba, 2015.p. 2.

LAFFIN, M. H. L. F; GAYA, S. M. Pesquisas e estudos sobre a formação inicial docente no campo da Educação de Jovens e Adultos. Revista Brasileira de Educação de Jovens e Adultos, 01 maio 2013.

MINAYO, M.C.S. Pesquisa social: Teoria, método e criatividade. 19 ed. Petrópolis: Vozes, 2001.

NÓVOA, A. (Org.). Profissão professor. Porto: Porto Editora, 1992.p.25.

PAIVA, J.; MACHADO, M. M.; IRELAND, T... (Org.). Educação de Jovens e Adultos: uma memória contemporânea. Brasília.1973. 
RIBAS, M. S. 'Ser professor' na educação de jovens e adultos: interfaces entre representações sociais de professores que atuam nessa modalidade de ensino na Rede Municipal de Curitiba e as políticas educacionais. $194 \mathrm{f}$. Dissertação (Mestrado em Educação). Pontifícia Universidade Católica do Paraná, 2013.

SANFELICE, J. L. Dialética e Pesquisa em Educação. In: LOMBARDI, J.C.; SAVIANI, D. (Orgs.). Marxismo e Educação: debates contemporâneos. $2^{\mathrm{a}} \mathrm{ed}$. Campinas, SP: Autores Associados: Histedbr, 2008.

SCHEIBE, L. Perspectivas para uma política de formação com as novas diretrizes do curso de pedagogia. Ciência \& Opinião (Impresso), 2006.

SOARES, L. Avanços e desafios na formação do educador de jovens e adultos. In: MACHADO, M. M. (Org.). Formação de educadores de jovens e adultos. Brasília: Secad/MEC, Unesco, 2008. p.65.

SOARES, L. As especificidades na formação do educador de jovens e adultos: um estudo sobre propostas de EJA. Educ. rev. [online]. 201 1, v.27, n.2, p. 315.

Recebido em: 12 de março de 2019 